\title{
Editorial
}

\section{Cuidado sociocultural na cronicidade: em busca de um cuidado que faça sentido}

\section{Cuidado sociocultural en el sentido práctico: en busca del cuidado con sentido}

\section{Sociocultural care in practicality: in search of care that makes sense}

\author{
Maria de Lourdes Denardin Budó
}

Enfermeira. Doutora. Professora do Departamento e do Programa de Pós Graduação em Enfermagem da Universidade Federal de Santa Maria/UFSM, Brasil.

Cómo citar esta editorial en edición digital: Budó, M. L. D (2016). Cuidado sociocultural na cronicidade: em busca de um cuidado que faça sentido. Cultura de los Cuidados (Edición digital),20(45).

Disponible en: < http://dx.doi.org/10.14198/cuid.2016.45.01>

Correspondencia: Universidade Federal de Santa Maria, Centro de Ciências da Saúde, Departamento de Enfermagem. Faixa Camobi, km 9, Campus Universitário. Camobi. 97105-900 - Santa Maria, RS - Brasil

Correo electrónico: lourdesd@via-rs.net

Recibido: Autora invitada

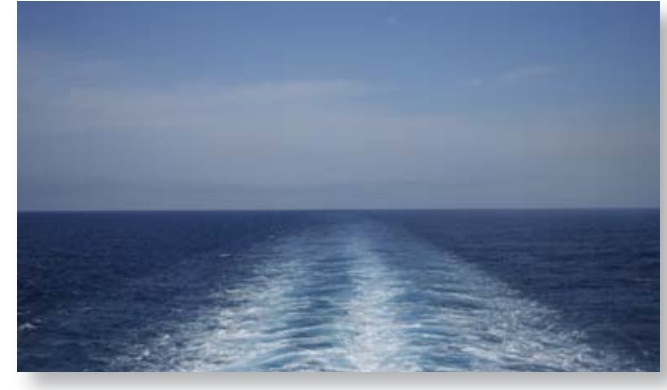

\section{RESUMEN}

La autora trata de la importancia de la vinculación entre enfermería y antropología, para que sea posible un cuidado adecuado a las perspectivas de las personas, especialmente en lo que se refiere a aquellas con enfermedades crónicas. De esa forma, el cuidado debe hacer sentido a las personas, tornándose imprescindible la aproximación de saberes profesionales y populares para un diálogo en busca de un cuidado satisfactorio.

Palabras-clave: Enfermería, Atención de Enfermería, Cultura.

\begin{abstract}
The author deals with the importance of linking nursing and anthropology for being possible a care which is appropriated to the people perspectives, especially regarding to those with chronic illnesses. Thus, the care should make sense to people, making it essential to approach professional and popular knowledges for a dialogue searching for a satisfactory care.
\end{abstract}

Keywords: Nursing, Nursing care, Culture.

\section{RESUMO}

A autora trata da importância da vinculação entre enfermagem e antropologia para que seja possível um cuidado adequado às perspectivas das pessoas, especialmente no que se refere àquelas com enfermidades crônicas. Desta forma, o cuidado deve fazer sentido para as pessoas, tornando-se imprescindível a aproximação de saberes profissionais e popu- 
lares para um diálogo em busca de um cuidado satisfatório.

Palavras-chave: Enfermagem, Cuidados de Enfermagem, Cultura.

Ao longo da história da humanidade o cuidado foi cultivado como o caminho para a manutenção da vida. Os sistemas de saúde existentes nas mais diversas culturas têm demonstrado suas possibilidades e limites. Em uma perspectiva antropológica, é possível reconhecer e respeitar as diferentes formas com que o ser humano tem enfrentado e solucionado seus problemas de saúde. Considera-se que existem sistemas de saúde que convivem e se entrelaçam em busca de soluções para o cuidado, não sendo o Sistema Profissional de Cuidados o único para o tratamento em saúde (Kleinman, 1981; Leininger, 1991).

Na presente reflexão, parte-se do pressuposto que nos aponta Langdon (2009, p. 323) de que a antropologia permite entender o ser humano e suas práticas em uma "perspectiva que reconheça e respeite a diversidade de soluções que as diversas culturas têm construído para explicar e atender os problemas de saúde e doença”.

O Sistema Profissional, em geral, ao adotar o sistema biomédico como principal paradigma do cuidado, entende e trabalha com o ponto de vista de que os saberes sobre saúde e doença são aplicáveis universalmente, sem considerar a influência cultural. No entanto, para a Antropologia, a biomedicina é também um "sistema cultural que emergiu através de um contexto histórico e cultural, com métodos particulares, mas não os únicos para lidar com a doença” Langdon (2009, p. 324).

$\mathrm{Na}$ enfermagem, durante a segunda metade do século XX, algumas autoras buscaram na antropologia os fundamentos para uma perspectiva relativista do cuidado, dentre elas, destacaram-se Leininger, nos EUA e Collière, na França que associaram, em seus estudos, as atividades de ações de enfermagem com a cultura Leininger (1991); Collière (1989). Ao longo dos últimos anos muitos estudos em todo o mundo avançaram nesta vinculação, no intuito de buscar formas de cuidar que façam sentido às pessoas, em suas culturas. Fazer sentido, não significa simplesmente adotar o cuidado cultural proposto pelas pessoas, mas sim, trabalhar com a perspectiva da educação em saúde, ao integrar o saber científico com o saber popular. As pessoas precisam entender aquilo que lhes é proposto como cuidado e torne significativo nas suas referências de cuidado, para então desenvolvê-lo.

Especialmente na cronicidade o desempenho das pessoas torna-se fundamental no transcorrer da enfermidade, visando o não agravamento e a sua melhora. Na vivência acadêmica, por meio de pesquisas empíricas por mais de vinte anos, constatou-se ainda a imposição de cuidados pelos profissionais de saúde. Trabalhou-se com pessoas em diversas situações crônicas de saúde-doença, buscando conhecê-las na tentativa de entender e interpretar os seus saberes e como se cuidavam nas situações de fragilidade. No geral, as pessoas cuidam-se associando o cuidado familiar ou cultural (aquele aprendido na família, no interior de sua cultura, ou ainda com o auxílio das redes sociais de apoio) ao cuidado profissional (Budó, 1994; Silva et al. 2013; Simon et al. 2015). Percebeu-se, nos estudos, que embora impregnada da história de vida das pessoas, a forma do viver e cuidar não é fechada para o conhecimento científico: ela se modifica à medida que novos conteúdos são absorvidos no contato com o conhecimento científico. $\mathrm{O}$ viver e o cuidado em saúde se encontram profundamente inter-relacionados, integrado na vida e cotidiano das pessoas. Muitas vezes, 
isso se manifesta conectando experiências atuais, muitas aprendidas no sistema profissional, com as antigas, aprendidas na família, no sistema popular. Em estudo realizado por Silva et al (2013, p.59), notou-se que a utilização conjugada de terapias popular e profissional, fundamentada na complementaridade de saberes, acontece com a finalidade de uma potencializar o efeito da outra. "Isso significa dizer que as práticas de vida são construídas por várias fontes de conhecimentos que vão sendo incorporados às experiências e sensações dos sujeitos e, mesmo pertencendo a um determinado grupo sociocultural, irão nortear a vida de cada integrante de maneira singular".

Essa forma de viver demonstra flexibilidade e maleabilidade porque permite filtrar aquilo que lhes interessa dos cuidados em saúde do sistema profissional. Portanto, não se constitui num sistema fechado em sua cultura, mas permite que ingresse em seu cotidiano somente aquilo que lhes interessa e que não venha contra seus sistemas de crenças. Parece que tudo passa por um sistema de referências que façam sentido no cuidado. Em todos os casos, a referência primeira é a família, na qual as decisões sobre como cuidar são tomadas. Neste sentido, há uma tendência de ser realizado primeiro o cuidado com as práticas aprendidas com as gerações. Após a avaliação da possibilidade ou não da melhora é que são buscados os auxílios externos. Em muitos casos, o próximo passo é a procura do sistema profissional, mas sempre tendo como referência a decisão familiar. Porém, não são todas as ideias e atos de cuidar que são absorvidos por eles, há uma seleção daquilo que lhes serve e não esbarra na essência dos seus valores ou vai contra o seu sistema cultural.

Há necessidade que o cuidado faça sentido para a pessoa com problemas de saúde. Torna-se fundamental que a pessoa, ao seguir um tratamento ou cuidado, perceba o que signifi- ca, isto é, conheça o porquê daquilo que está sendo orientado ou prescrito. Desta forma, é imprescindível a aproximação de saberes para um diálogo possível na busca por um cuidado satisfatório. Isso pode significar o resgate do conhecimento popular, na busca por um cuidado mais apropriado às necessidades das pessoas, que passa pela educação em saúde.

\section{REFERÊNCIAS}

- Kleinman, A (1980). Patients and Healers in the context of culture. London: Press LTDA.

- Leininger, M (1991). Culture care diversity and universality: a theory of nursing. New York: National League for Nursing Press.

- Collière, M. F (1989). Promover a vida: da prática das mulheres de virtude aos cuidados de enfermagem. Lisboa: Sindicato dos Enfermeiros Portugueses.

- Budó, M. L. D (1994). Cuidando e sendo cuidado: um modelo cultural de suporte à saúde em comunidade rural de descendentes de imigrantes italianos. (Dissertação de mestrado). Programa de Pós-graduação em Extensão Rural, Universidade Federal de Santa Maria: Santa Maria/RS/Brasil.

- Langdon, E. J. (2009). Dialogando sobre o processo saúde/doença com a Antropologia: entrevista com Esther Jean Langdon. Revista Brasileira de Enfermagem, 62(2), 323-6. Recuperado de http:// www.scielo.br/scielo.php?script $=$ sci_arttext\&pid $=$ S0034-71672009000200025.

- Silva, F.M., Budó, M.L.D., Garcia, R.P., Sehnem, G.D., Schimith, M.D. (2013). Práticas de vida de portadores de hipertensão arterial. Revista de enfermagem da UERJ, 21(1), 54-9. Recuperado de http://www.facenf.uerj.br/ v21n1/v21n1a09.pdf.

- Simon, B.S., Budó, M.L.D., Schimith, M.D., Garcia, R.P., Gomes, T.F., Carvalho S.O.R.M. (2015). "Sempre ajudando em uma coisa ou outra": rede social da família da pessoa com estomia. Revista eletrônica de enfermagem, 17(2), 370-8. Recuperado de http://dx.doi.org/10.5216/ ree.v17i2.29786. 